\title{
Histochemical characterization, distribution and morphometric analysis of NADPH diaphorase neurons in the spinal cord of the agouti
}

\author{
Marco Aurélio M. Freire ${ }^{1,2,4}$, Suzane C. Tourinho ${ }^{3, \dagger}$, Joanilson S. Guimarães ${ }^{1,2}$, \\ Jorge Luiz F. Oliveira', Cristovam W. Picanço-Diniz' ${ }^{1}$, Walace Gomes-Leal ${ }^{3}$ and \\ Antonio Pereira, $\mathbf{J r}^{2,3, *}$ \\ 1. Laboratory of Functional Neuroanatomy, Institute of Biological Sciences, Federal University of Pará, Belém, Brazil \\ 2. Laboratory of Cellular Neurobiology, International Institute for Neurosciences of Natal Edmond and Lily Safra, Natal, Brazil \\ 3. Laboratory of Experimental Neuroprotection and Neuroregeneration, Institute of Biological Sciences, Federal University of Pará, \\ Belém, Brazil
}

Edited by: Kathleen S. Rockland, RIKEN Brain Science Institute, Japan

Reviewed by: Marcello G. Rosa, Monash University, Australia

Paul Manger, University of the Witwatersrand, South Africa

\begin{abstract}
We evaluated the neuropil distribution of the enzymes NADPH diaphorase (NADPH-d) and cytochrome oxidase (CO) in the spinal cord of the agouti, a medium-sized diurnal rodent, together with the distribution pattern and morphometrical characteristics of NADPH-d reactive neurons across different spinal segments. Neuropil labeling pattern was remarkably similar for both enzymes in coronal sections: reactivity was higher in regions involved with pain processing. We found two distinct types of NADPH-d reactive neurons in the agouti's spinal cord: type I neurons had large, heavily stained cell bodies while type II neurons displayed relatively small and poorly stained somata. We concentrated our analysis on type I neurons. These were found mainly in the dorsal horn and around the central canal of every spinal segment, with a few scattered neurons located in the ventral horn of both cervical and lumbar regions. Overall, type I neurons were more numerous in the cervical region. Type I neurons were also found in the white matter, particularly in the ventral funiculum. Morphometrical analysis revealed that type I neurons located in the cervical region have dendritic trees that are more complex than those located in both lumbar and thoracic regions. In addition, NADPH-d cells located in the ventral horn had a larger cell body, especially in lumbar segments. The resulting pattern of cell body and neuropil distribution is in accordance with proposed schemes of segregation of function in the mammalian spinal cord.
\end{abstract}

Keywords: pain, spinal cord, nitric oxide, interneurons, cytochrome oxidase, rodents, evolution

\section{INTRODUCTION}

Since the early 1960s it has been shown that the enzyme nicotinamide adenine dinucleotide phosphate diaphorase (NADPH-d) reveals a sub-population of inhibitory neurons in the mammalian central nervous system (CNS) (Thomas and Pearse, 1964). Later, it was demonstrated that NADPH-d corresponds to nitric oxide synthase enzyme (NOS), which catalyzes production of nitric oxide (NO) (Dawson et al., 1991;

*Correspondence: Antonio Pereira, Laboratory of Experimental Neuroprotection and Neuroregeneration, Institute of Biological Sciences, Federal University of Pará (UFPA), Rua Augusto Correa 01, Guamá, Belém, PA, 66075-900, Brazil. e-mail: apereira@ufpa.br

'Marco Aurélio Freire and Suzane Tourinho contributed equally to this article.

Article contributions: AP, MAMF and WGL conceived and designed the experiments; SCT, JSG, JLF0 and MAMF performed the experiments; MAMF, JSG, JLF0 and SCT analyzed the data; MAMF and AP designed and organized the illustrations; AP and CWPD contributed with reagents/materials/analysis tools; AP, MAMF and WGL wrote the paper.

Received: 24 January 2008; paper pending published: 04 February 2008; accepted: 08 May 2008; published online: 26 May 2008.

Citation: Front. Neuroanat. (2008) 2: 2. doi: 10.3389/neuro.05.002.2008

Copyright (c) 2008 Freire, Tourinho, Guimarães, Oliveira, Picanço-Diniz, Gomes-Leal and Pereira. This is an open-access article subject to an exclusive license agreement between the authors and the Frontiers Research Foundation, which permits unrestricted use distribution, and reproduction in any medium, provided the original authors and source are credited.
Hope et al., 1991), a highly diffusible signaling molecule. NO is involved with several physiological and pathological processes in the nervous system, including synaptic plasticity and local regulation of blood flow (Contestabile, 2000; Estrada and DeFelipe, 1998; Holscher, 1997; ladecola, 1993; Wallace et al., 1996; see Calabrese et al., 2007 for a recent review). NADPH-d histochemistry has since been used as an indirect method for revealing the distribution of $\mathrm{NO}$ in aldehyde-fixed brains (Scherer-Singler et al., 1983).

Two distinct types of non-pyramidal, NADPH-d-containing cells have been consistently identified in the mammalian CNS: a more reactive group, with a Golgi-like appearance (type I cells), and a weakly stained sub-population (type II cells) (Luth et al., 1994). Both are co-localized with GABA in cortical neurons, but type II neurons also express calbindin (Yan et al., 1996). Type I neurons have large, darkly stained cell bodies and dendritic tress (Luth et al., 1994) and are present in the brain of all mammals examined, from echidna to primates (Hassiotis et al., 2005; Yan and Garey, 1997). Type II neurons, conversely, are weakly stained, with small cell bodies and few or no labeled processes (Luth et al., 1994), and are reported to be especially numerous in the primate brain (Sandell, 1986; Yan and Garey, 1997). In the present work, we will report data from type I neurons, henceforth called NADPH-d neurons.

The distribution of NADPH-d/NOS neurons has been described in the CNS of several mammalian orders (Barone and Kennedy, 2000; 
Cruz-Rizzolo et al., 2006; Freire et al., 2007; Gonchar et al., 2008; Luth et al., 1994; Mizukawa et al., 1989; Ouda et al., 2003; Pereira et al. 2000; Vincent and Kimura, 1992; Wiencken and Casagrande, 2000; Xiao et al., 1996). In the rat brain, for instance, it was shown that NADPH-d neurons are also GABAergic (Valtschanoff et al., 1993) and amount to approximately $2 \%$ of the cortical cell population (Valtschanoff et al., 1993; Vincent and Hope, 1992). NADPH-d/NOS neurons were also detected in the spinal cord (Anderson, 1992; Dun et al., 1993; Kluchova et al., 2002; Marsala et al., 1997; Saito et al., 1994; Valtschanoff et al., 1992a,b) and were reported to be more intensely labelled at laminae I-IV and X of the entire spinal cord and at the intermediolateral column (IML) of both the thoracic and lumbar segments (Saito et al., 1994).

A considerable amount of evidence has implicated NO as a nociceptive mediator in both peripheral tissues and the spinal cord. It has been proposed, for instance, that hyperalgesia is mediated by activity-dependent long-term potentiation (LTP) being induced in spino-peraqueductal gray projections neurons located in the spinal dorsal horn lamina I (Ikeda et al., 2006) and that NO is essential for its induction (Ikeda et al. 2006). Recently, it was shown in rats that LTP in lamina I neurons could be induced by NO secreted by interneurons located in laminae II and III (Ruscheweyh et al., 2006).

Cytochrome oxidase (CO) is a key mitochondrial enzyme involved with oxidative metabolism (see Wong-Riley, 1989 for review). The strict coupling observed between neuronal activity and oxidative metabolism (Kasischke et al., 2004) justifies the use of $\mathrm{CO}$ as an endogenous metabolic marker in the brain. Analysis of $\mathrm{CO}$ distribution in the CNS, for instance, has helped to unveil key principles of compartmental organization in the brain (Freire et al., 2004, 2005; Wong-Riley, 1979; Wong-Riley and Welt, 1980), and the spinal cord of several mammalian species (Wong-Riley and Kageyama, 1986).

Our animal model, the agouti (Dasyprocta ssp., Dasyproctidae: Rodentia), is a medium-sized terrestrial and burrowing rodent (about ten times as heavy as the rat) with a widespread distribution over Central and South American Neotropical forests (Silvius and Fragoso, 2003). Agoutis are diurnal animals that rely mostly on a frugivorous diet, usually manipulating seeds with high dexterity with their forelimbs (Henry, 1999). Agoutis play a critical role on dispersing tree and plant seeds due to their caching behaviour (Silvius and Fragoso, 2003). This behaviour also underlies the necessity of a well-developed spatial memory for successful seed retrieval. The agouti is always on the lookout for predators, and possesses a welldefined retinal visual streak that, together with its lateralized eyes (Silveira et al., 1989), provides for good panoramic vision. The agouti has been successfully used as a model for comparative studies of cortical organization (Elston et al., 2006; Picanço-Diniz et al., 1989; Rocha et al., 2007).

In this work we evaluate the neuropil reactivity, distribution pattern and morphometrical characteristics of NADPH-d neurons in different segments along the spinal cord of the agouti. Our results show that NADPH-d neurons are more numerous in the dorsal horn, more specifically in laminae I and II, and around the central canal (lamina X). Morphometric analysis shows that while NADPH-d neurons have cell bodies that are larger in the ventral horn, their dendritic fields are larger and more complex in the dorsal horn, especially in cervical segments. The spatial distribution of $\mathrm{CO}$ and NADPH-d neuropil enzymatic activity is somewhat similar, appearing more intense in the superficial laminae of the cervical and lumbar enlargements, which are associated with innervation of the fore- and hindlimb, respectively. The resulting pattern of cell body and neuropil distribution is in accordance with known schemes of segregation of function in the mammalian spinal cord and further illuminates the role played by NO in dorsal horn circuitry.

\section{MATERIALS AND METHODS Animals}

We used five adult male agoutis (Dasyprocta spp) $(2.7-3.2 \mathrm{~kg}$ ) in the present study. Animals were donated by The Emilio Goeldi Museum, under license of the Brazilian Institute for Environmental Protection (IBAMA, license 207419-0030/2003). The experimental protocols are in accordance with NIH Guidelines for the Care and Use of Laboratory Animals. We made all efforts to use as few animals as possible and to minimize unnecessary animal discomfort, distress and pain.

\section{Perfusion and histological procedures}

Animals were deeply anesthetized with an intramuscular injection of a mixture of ketamine hydrochloride $(90 \mathrm{mg} / \mathrm{kg}$ ) and xylazine hydrochloride $(10 \mathrm{mg} / \mathrm{kg})$. After extinction of the corneal reflex, animals were perfused transcardially with $500 \mathrm{ml}$ of heparinized $0.9 \%$ saline solution followed by $2,000 \mathrm{ml}$ of $4 \%$ paraformaldehyde (Sigma Company, USA) in $0.1 \mathrm{M}$ phosphate buffer (PB). The spinal cord was dissected and stored in $0.1 \mathrm{M}$ Tris buffer $\mathrm{pH}$ 8.0. Before sectioning, segments of equal length from the cervical enlargement (C4-T1), thoracic region (T7-T10) and lumbar enlargement (L4-S1) were separated. The spinal cord blocks were cut into $200 \mu \mathrm{m}$-thick coronal sections using a Vibratome (Pelco International, Series 1000).

\section{Histochemical processing}

We used adjacent sections to reveal the enzymatic activity of NADPH-d and CO. NADPH-d was revealed with the indirect method (modified from Scherer-Singler et al., 1983) as follows: free-floating sections were incubated in a medium containing $0.6 \%$ malic acid, $0.03 \%$ nitroblue tetrazolium, $1 \%$ dimethylsulfoxide, $0.03 \%$ manganese chloride, $0.5 \% \beta$-NADP and $1.5-3 \%$ Triton X-100 in $0.1 \mathrm{M}$ Tris buffer, $\mathrm{pH} 8.0$ and protected from light. Sections were monitored every $60 \mathrm{~min}$ to avoid overstaining. The incubation period lasted from 6 to $7 \mathrm{~h}$ and was interrupted by rinsing sections in $0.1 \mathrm{M} \mathrm{PB} \mathrm{(pH} \mathrm{7.4).} \mathrm{The} \mathrm{criteria} \mathrm{to} \mathrm{stop} \mathrm{the} \mathrm{reaction} \mathrm{were} \mathrm{the}$ presence of strongly stained cell bodies and a less intense but heterogeneously labelled neuropil.

CO histochemistry was performed in adjacent, $200 \mu \mathrm{m}$-thick coronal sections from the same spinal cord segments (Wong-Riley, 1979). Briefly, sections were incubated in a solution containing $0.05 \%$ diaminobenzidine (DAB), $0.03 \%$ cytochrome $c$ and $0.02 \%$ catalase. The reaction was monitored every $30 \mathrm{~min}$ in order to avoid overstaining. Similar to NADPH-d, sections were incubated for the same period of time and in the same solution for all animals. The duration of incubation ranged from $7-8 \mathrm{~h}$, and was interrupted by rinsing the sections five times in $0.1 \mathrm{M} \mathrm{PB}(\mathrm{pH}$ 7.4). All reagents were purchased from Sigma Company (USA).

Additional alternate sections were Nissl-stained for cytoarchitectonic analysis. Sections were mounted on gelatin-coated glass slides, left to air-dry overnight, dehydrated and coverslipped with Entellan (Merck).

\section{Qualitative and quantitative analyses}

Both NADPH-d and CO stained sections were qualitatively surveyed under light microscopy and images of representative fields were obtained with a digital camera (Nikon Coolpix 950E) attached to an optical microscope (Nikon AFX-DX Optiphot-2). A few selected NADPH-d neurons, from each region of interest, were also photographed for the illustrations. Only the global contrast, and/or brightness of pictures were adjusted using Photoshop CS (Adobe Systems, Inc., USA).

We used the software Neurolucida (MicroBrightField Inc., USA) to characterize the spatial distribution of NADPH-d neurons in ten sections obtained from cervical, thoracic and lumbar regions from each animal. Within each section, we counted the number of cells in the following regions: dorsal horn (laminae I-IV), central canal (lamina X) and ventral horn (laminae VII-IX). In order to obtain an unbiased estimate of cell numbers, we applied the Abrecrombie's correction factor (Abercrombie, 1946; see Williams and Rakic, 1988 for details), which compensates for the overcounting of sectioned profiles, using the equation: $P=A(M / M+L)$, where $P$ is the corrected value, $A$ is the raw density measure, $M$ is the section's thickness (in micrometers) and $L$ is the average diameter of cell bodies along the axis perpendicular to the plane of section. Descriptive statistics was obtained for all groups and we evaluated differences among groups by one-way analysis of variance (ANOVA) followed by the 
Newman-Keuls post hoc test. Statistical significance was set at $95 \%$ confidence level $(\alpha<0.05)$. Table 1 depicts the average diameter of spinal cord cells. In general, the largest neuronal cell bodies were located in the ventral horn $(p<0.05)$.

We chose thirty cells of each region (dorsal horn, central canal and ventral horn) for reconstruction using the Neurolucida software. The software ran in a PC attached to a Nikon microscope $(60 \times$ objective) equipped with a motorized stage. The criterion to select cells for analysis was the presence of a complete, uncut dendritic arborization. The following parameters were measured using the Neuroexplorer software (MicroBrightField Inc., USA): dendritic field size (the area contained within a polygon joining the outermost distal tips of the dendrites), cell body area (values expressed in $\mu \mathrm{m}^{2}$ ), number of branch points and number of dendrites. Mean values were compared amongst groups by ANOVA followed by Newman-Keuls post hoc test, as previously described.

\section{RESULTS}

\section{General morphological considerations}

The gross cytoarchitectonic arrangement of the agouti's spinal cord, stained with cresyl violet, was similar to that observed in other mammalian species such as the cat (Rexed, 1952, 1954) and the rat (Molander et al., 1984, 1989) (Figure 1). Based on this similarity, we used the same cytoarchitectonic nomenclature employed for other mammals (Rexed, 1952, 1954), defining three distinct regions across segments dorsal horn (laminae I-IV), ventral horn (laminae VII-IX) and central canal (lamina X).

The overall neuropil reactivity revealed by the enzymes NADPH-d and $\mathrm{CO}$ was also similar to that reported for other mammalian species (Kluchova et al., 2001; Reuss and Reuss, 2001; Saito et al., 1994;
Valtschanoff et al., 1992a; Wong-Riley and Kageyama, 1986) (Figure 1). The most intense reactivity was observed in the substantia gelatinosa (lamina II) (Figure 1).

\section{Distribution of NADPH-d neurons}

Two types of reactive neurons can be readily identified in the spinal cord of the agouti: type I and type II cells (Luth et al., 1994). Both correspond to aspiny, non-pyramidal neurons with distinct reactivity profiles (Figure 2). Type I neurons have the largest cell bodies and are more intensely labeled, showing in high-contrast details of both the cell body and the dendritic tree. Type II neurons, on the other hand, have a ghostlike appearance against the nonspecific background, with only their tiny soma being barely visible (Figure 2).

The distribution of type I cells was examined in coronal sections of the spinal cord (Figure 3A). In every segment, the number of NADPH-d cells is greater in the dorsal horn and the central canal than in the ventral horn $(p<0.05$; Figure 3B). The exception is seen in the thoracic segment, where the distribution of labeled cells is more homogeneous ( $p>0.05$; Figure 3B). When comparing the distribution of cells in the dorsal horn and the central canal, however, the number of NADPH-d neurons is significantly greater in the former than in the later in both the lumbar $(p<0.05)$ and cervical segments $(p>0.05)$.

Another comparison shows that NADPH-d neurons have a different distribution along spinal segments. For instance, labeled neurons are always found in greater number in the cervical segment $(p<0.05$; Figure $3 \mathrm{~B}$ ), with the exception of the dorsal horn, which has a similar number of neurons in both the cervical and lumbar enlargements $(p>0.05)$. For the central canal, however, all segmental comparisons show difference, and more neurons are labeled in the lumbar enlargement, followed by the cervical enlargement and thoracic segments

Table 1. Average diameters of NADPH-d type I neurons across spinal cord. Cell bodies of ventral horn neurons are larger than other regions.

\begin{tabular}{lcccc}
\hline Regions Segments & Cervical (1) & Thoracic (2) & Lumbar (3) & ANOVA/Newman Keuls \\
\hline Dorsal horn & $20.53 \pm 0.62$ & $17.42 \pm 0.43$ & $18.98 \pm 0.44$ & $1-2(p>0.05)$ \\
Central canal & $22.88 \pm 0.50$ & $19.81 \pm 1.14$ & $23.28 \pm 0.49$ & $1-3(p<0.05)$ \\
Ventral horn & $25.41 \pm 0.51$ & $23.74 \pm 0.50$ & $30.16 \pm 0.56$ & $2-3(p<0.05)$ \\
\hline
\end{tabular}
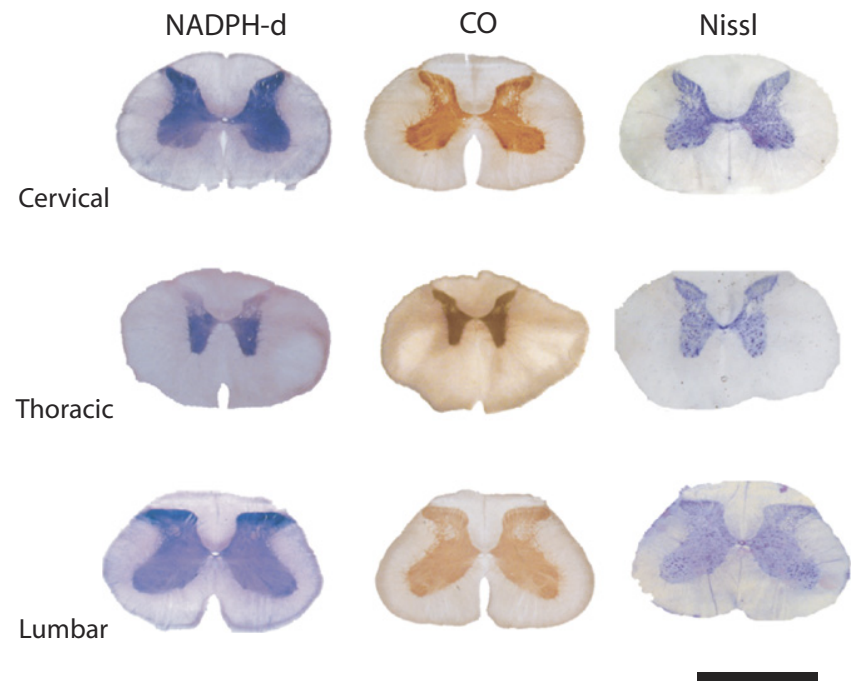

Figure 1. NADPH diaphorase and cytochrome oxidase reactivity in coronal sections of the agouti's spinal cord. The enzymatic reaction pattern is illustrated in alternate sections of three spinal cord segments. The spinal cord cytoarchitectonic organization can be observed in alternate sections stained with cresyl violet. Neuropil reactivity for both NADPH-d and $\mathrm{CO}$ is higher in the dorsal horn, except in thoracic segments. Scale bar: $10 \mathrm{~mm}$.

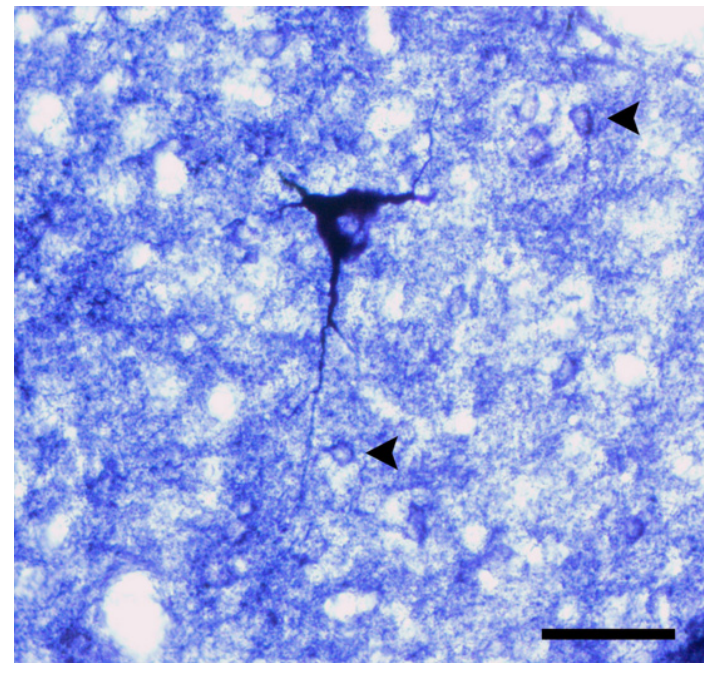

Figure 2. Comparative morphology of types I and II neurons in the central canal of the lumbar segment in agouti's spinal cord. Note both the small size of the cell body and the weakly stained dendritic arbor of type II neurons (arrowheads) when compared to the much-larger type I cell. Scale bar: $30 \mu \mathrm{m}$. 


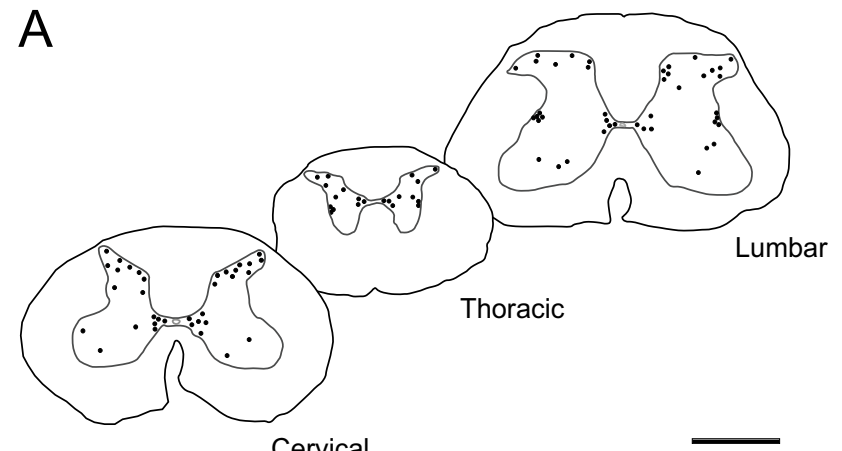

$\mathrm{B}$ ses points to a heterogeneous distribution of NADPH-d neurons across spinal cord segments (A), confirmed by quantitative analysis depicted in the histogram (B). For any given spinal segment, the number of NADPH-d cells is greater in both the dorsal horn and central canal than in the ventral horn (B). In addition, these cells are found in greater number in both the cervical and lumbar segments (B). Asterisks in horizontal bars indicate statistically significant comparisons $\left({ }^{*} p<0.05 ; * * p<0.01 ;\right.$ ANOVA/Newman-Keuls post hoc test). Scale bar in A: $10 \mathrm{~mm}$.

A

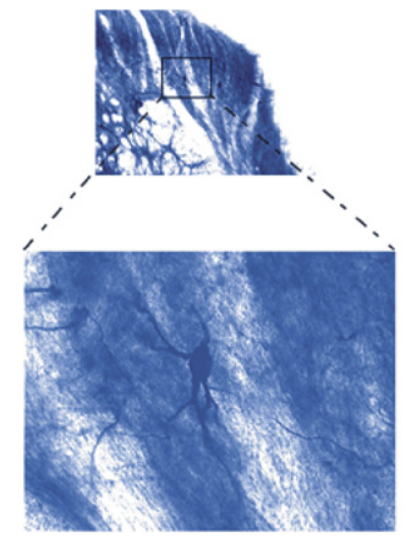

Dorsal horn
Gray matter

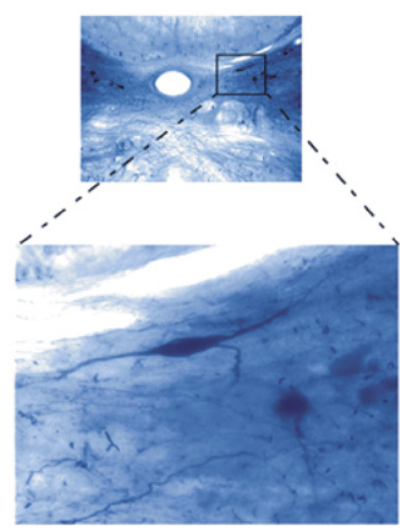

Central canal

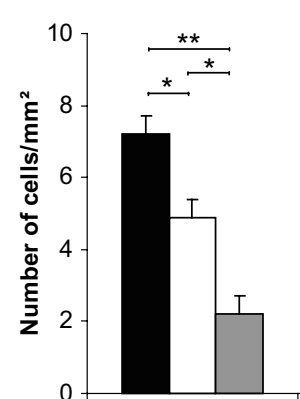

Cervical

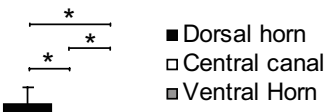

Lumber 口Ventral Horn

Figure 4. Morphology of NADPH-d neurons located in the spinal cord. Gray matter neurons have a varied morphology, including poorly ramified bipolar neurons from the central canal and extensively ramified multipolar cells from the dorsal horn of the cervical enlargement (A). The dendritic arborization of white matter cells is exuberant, frequently projecting towards the gray matter (B). Scale bars: $100 \mu \mathrm{m}$ (lower magnification); $50 \mu \mathrm{m}$ (enlargements).

(Figure 3B; $p<0.05)$. In the ventral horn, the number of NADPH-d neurons is greater in the lumbar segment than in either the cervical or the thoracic segments $(p<0.05)$, both showing no statistical difference between them (Figure 3B; $p>0.05$ ).

\section{Morphometric analysis of NADPH-d neurons}

We evaluated the morphology of reactive NADPH-d neurons both qualitatively and quantitatively. NADPH-d neurons are present throughout the rostrocaudal axis of the spinal cord (Figure $3 \mathrm{~A}$ ) and have a varied morphology, including poorly ramified bipolar neurons in the central canal and extensively ramified multipolar cells in the dorsal horn of the cervical enlargement (see examples in Figure 4).

NADPH-d neurons are present in all laminae of both the cervical and lumbar enlargements, but are mostly found in the superficial layers of the dorsal horn (laminae I-IV) and clustered around the central canal (lamina X) (Figures $3 \mathrm{~A}$ and 4). Cells in the cervical enlargement have the most complex pattern of dendritic arborization of all segments, especially in the dorsal horn (Figure 4). NADPH-d neurons in the ventral horn display the simplest arborization pattern, regardless of segmental location (Figures 4 and 5).
The dendritic arborization of NADPH-d cells in the thoracic segment is relatively poor when compared to cells in both the cervical and lumbar enlargements (Figure 5). In the thoracic segment, NADPH-d neurons are mostly located at Rexed's laminae I-IV, VII, IX and X (Figure 4) and the IML. Thoracic NADPH-d cells have in general a multipolar aspect and exhibit a compact dendritic arbor (Figure 5), with cells located in the dorsal horn and central canal having the most prominent dendritic arborization (Figure 5).

Similar to what is observed in the cervical segment, NADPH-d cells located in the inferior portion of both the dorsal horn and the central canal of the lumbar enlargement also have a relatively complex morphology (Figure 5). Although neurons in the ventral horn display intense NADPH$d$ reactivity, they tend to have stumpy dendritic arbors (Figure 5).

We also observed scattered NADPH-d neurons located in the white matter of every spinal cord segment, mostly in the ventral and dorsal funiculi (Figure 4B). The dendritic tree of these cells shows a complex ramification pattern, especially in the ventral white matter. These cells are commonly found in regions bordering gray matter, usually projecting their dendrites toward it. 
Cervical

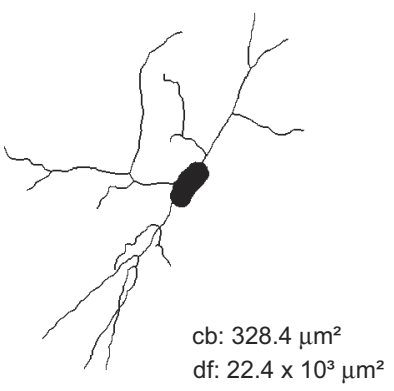

Dorsal horn

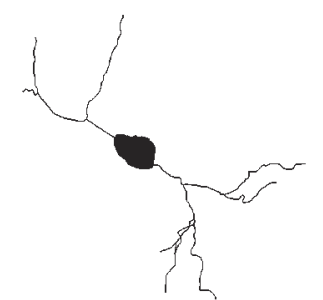

cb: $405.2 \mu \mathrm{m}^{2}$

df: $16.5 \times 10^{3} \mu m^{2}$

Central canal

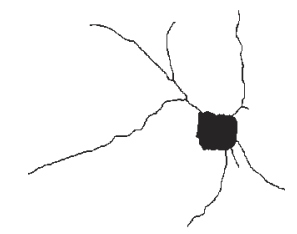

cb: $467.7 \mu \mathrm{m}^{2}$

Ventral horn
Thoracic

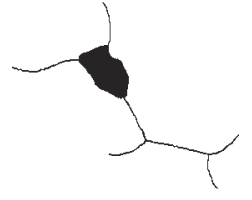

cb: $260.2 \mu \mathrm{m}^{2}$

df: $9.5 \times 10^{3} \mu \mathrm{m}^{2}$
Lumbar

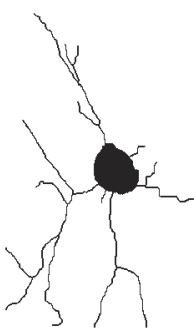

cb: $285.7 \mu \mathrm{m}^{2}$

df: $19.5 \times 10^{3} \mu \mathrm{m}^{2}$

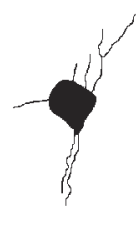

cb: $337.6 \mu \mathrm{m}^{2}$

df: $5.6 \times 10^{3} \mu \mathrm{m}^{2}$

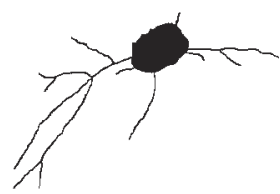

cb: $419.5 \mu \mathrm{m}^{2}$

df: $9.6 \times 10^{3} \mu \mathrm{m}^{2}$

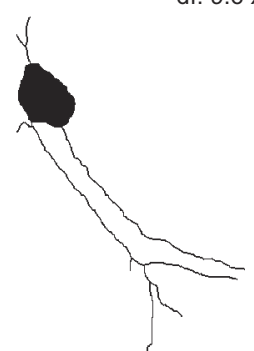

$\mathrm{cb}: 622.6 \mu \mathrm{m}^{2}$

df: $14.4 \times 10^{3} \mu \mathrm{m}^{2}$

Figure 5. Computer-aided reconstruction of NADPH-d neurons across distinct regions of the spinal cord. Cells in the cervical enlargement, especially in the dorsal horn and central canal, possess a more elaborated dendritic arborization than those located in other segments. Cells in thoracic segments are poorly ramified. Legends: cb: cell body area in $\mu m^{2}$; df: dendritic field coverage area in $\mu m^{2}$. Scale bar: $30 \mu m$.

The quantitative analysis confirmed and expanded the qualitative description of morphological characteristics of NADPH-d neurons across spinal cord segments. Cells located in the ventral horn have the largest cell body, especially in the lumbar segment $(p<0.01)$ (Figure 6A). Conversely, cells in the dorsal horn (especially in cervical and lumbar segments) have a larger dendritic field coverage $(p<0.01)$ (Figure 6B). Overall, the dendritic tree of neurons in the thoracic segment covers a volume smaller than that of cells located in other segments $(p<0.05$; $p<0.01$ ) (Figure 6B). Two other measured parameters, i.e., number of ramification points and number of dendrites by order, follow the same trend: the neurons in the dorsal horn of the cervical and lumbar enlargements have a greater number of branch points than cells in the same location in the thoracic segment (Figure $6 \mathrm{C}$ ). This is also observed in the ventral horn, although cells in this region are noticeably less ramified than cells in the dorsal horn (Figure 6C) $(p<0.05)$. Only in the central canal of the thoracic segment do neurons have more branch points than those in the lumbar enlargement, but not the cervical enlargement (Figure 6C).

The neurons located in the dorsal horn of the cervical and lumbar enlargements have the most exuberant dendritic arborization (Figure 7A, $p<0.05)$, exhibiting up to fifth order dendrites, especially in the central canal (Figure 7B). Conversely, neurons of the thoracic segment ramify only to third order dendrites (Figure 7B). We found a greater density of branches in the second order dendrites of cells located in both the dorsal horn and central canal of the cervical enlargement (Figure 7B) $(p<0.01)$. Although less noticeable, the same trend is observed in the lumbar enlargement, except for the ventral horn, where the peak of branching is observed in first order dendrites (Figure 7B, $p<0.01$ ). In the thoracic segment, in a way similar to the lumbar enlargement, cells located in the ventral horn have the most exuberant ramification pattern (Figure 7B, $p<0.01$ ).

\section{DISCUSSION}

In the present work, we evaluated the enzymatic reactivity of NADPH-d and $\mathrm{CO}$ in coronal sections of the spinal cord of the agouti. Our main results are the following. First, the reactivity pattern for both enzymes is very similar throughout the spinal cord. Second, NADPH-d neurons are heterogeneously distributed across distinct spinal cord segments, with more neurons located in the dorsal horn and around the central canal in the cervical and lumbar enlargements. Third, the neurons found in the cervical enlargement are always more numerous and more ramified 
A

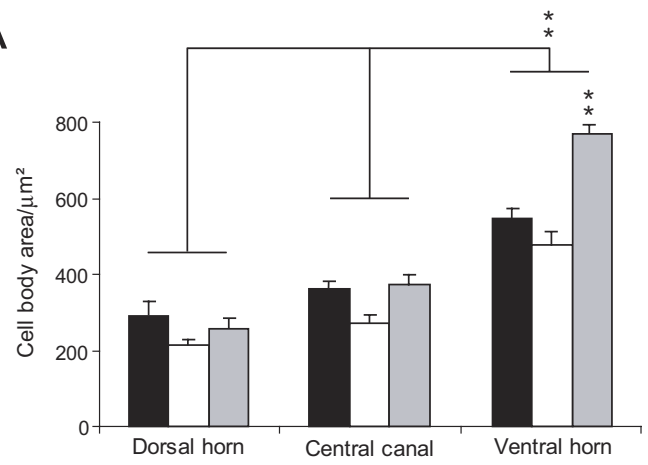

B

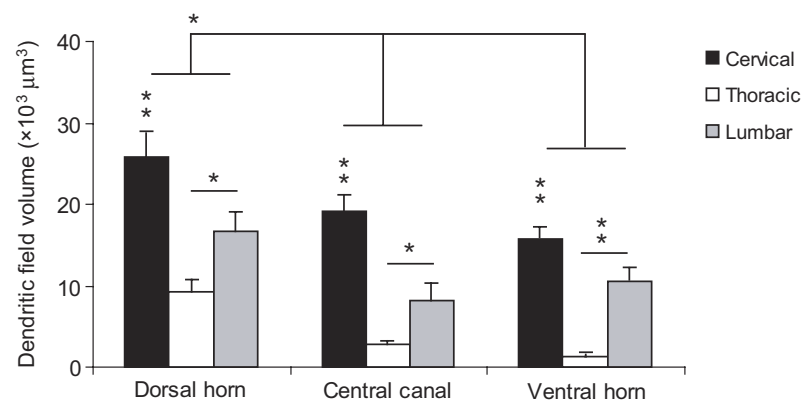

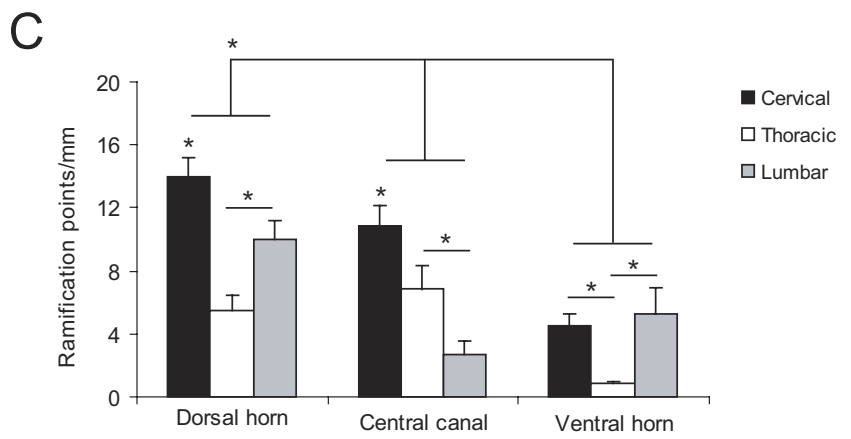

Figure 6. Comparative morphometry of spinal cord's NADPH-d neurons. Cells located in the ventral horn have the largest cell bodies, especially in lumbar segments (A). Conversely, cells found in the dorsal horn (especially in both cervical and lumbar segments) possess a larger dendritic coverage (B). In addition, neurons found in the dorsal horn of the cervical and lumbar segments have a greater number of branch points than cells found in the same region of the thoracic segment (C) Asterisks in horizontal bars indicate statistically significant comparisons ( $* p<0.05, * * p<0.01$, ANOVA/Newman-Keuls post hoc test).

than those found in other segments. The significance of these findings is discussed below.

\section{Cytoarchitectonic organization of the agouti's spinal cord: similarities with other mammalian species}

Our results show that the agouti's spinal cord possesses a laminar organization that follows the classical pattern described by Rexed in the cat (Rexed, 1952, 1954). It is also very similar to the organization described for the rat (Molander et al., 1984, 1989), corroborating the claim that the laminar scheme proposed by Rexed is valid for all mammals, including man (Schoenen, 1973).

The histochemical reaction pattern for NADPH-d was spatially heterogeneous in coronal sections, as described in other species (Dun et al., 1993; Wong-Riley and Kageyama, 1986). Neuropil was usually more reactive in the dorsal horn of the cervical and lumbar enlargements, but not the thoracic segment (see Figure 1). The superficial laminae I and II are the target of inputs from nociceptive receptors from the periphery. Hyperalgesia is caused by inflammation and injury of peripheral tissues and is thought to be mediated by the amplification of nociceptive information in dorsal horn projection neurons (Woolf, 1983). It has been proposed that NO in this region could be involved with LTP underlying hyperalgesia (Ikeda et al., 2006). Additionally, there is ample, consistent evidence of the involvement of NO in nociception provided, for instance, by the pharmacological blockade of NOS using the intravenous administration of $\mathrm{N}$-omeganitro-L-arginine methyl ester (L-NAME) (Yonehara et al., 1997).

\section{Morphology and distribution of NADPH-d neurons in the agouti's spinal cord: possible functional significance}

Overall, the laminar distribution of NADPH-d neurons in the spinal cord of the agouti is similar to that described for other mammalian species, including the rat (Anderson, 1992; Saito et al., 1994; Spike et al., 1993), the rabbit (Kluchova et al., 2002), the hamster (Reuss and Reuss, 2001), the monkey (Dun et al., 1993) and humans (Foster and Phelps, 2000; Smithson and Benarroch, 1996). We show that NADPH-d neurons tend to concentrate in three main regions: the dorsal horn, the IML and central canal (see Figure 3A). Other studies, however, show a qualitatively distinct distribution pattern in other species (Blottner and Baumgarten, 1992; Mizukawa et al., 1989). Blottner and Baumgarten (1992), for instance, report that NADPH-d neurons are found only in the IML of the rat. Mizukawa et al. (1989), on the other hand, describe a relative absence of NADPH-d neurons in the same region in the cat's spinal cord. Other studies also fail to show the presence of NADPH-d neurons in the ventral horn of the rat (Kluchova et al., 2001; Spike et al., 1993) and the rabbit's spinal cord (Kluchova et al., 2001). Such differences are probably related to methodological issues, instead of genuine differences among species. For instance, the period of tissue incubation in Blottner and Baumgarten's study (about $30 \mathrm{~min}$ ) is much shorter than ours (at least $6 \mathrm{~h}$ ). In our experience, a longer incubation period is necessary to allow the proper visualization of the population of NADPH-d neurons.

We were able to identify two distinct types of NADPH-d reactive neurons in the spinal cord: a more reactive group, with a Golgi-like appearance (type I) and a small, weakly reactive subpopulation (type II) (Luth et al., 1994). These results are similarly observed in other mammalian species (Dun et al., 1993; Saito et al., 1994), suggesting that the presence of both types of NADPH-d neurons is universal in the mammalian spinal cord. Yan et al. (1996) described a strict co-localization of type II neurons with both GABA and calbindin in the primate cortex. The same authors also proposed that type II neurons are typical of the brain of higher mammals, such as primates (Yan et al., 1996). Our own results in both the rat and the mouse show that this conclusion has to be reconsidered: the brain of rodents also has a large population of type II neurons (Freire et al., 2004, 2005). Type II neurons, however, are much harder to discriminate than type I neurons in the mammalian brain and are very sensitive to overfixation (Freire et al., 2005). Thus, it is easy to overlook 
A

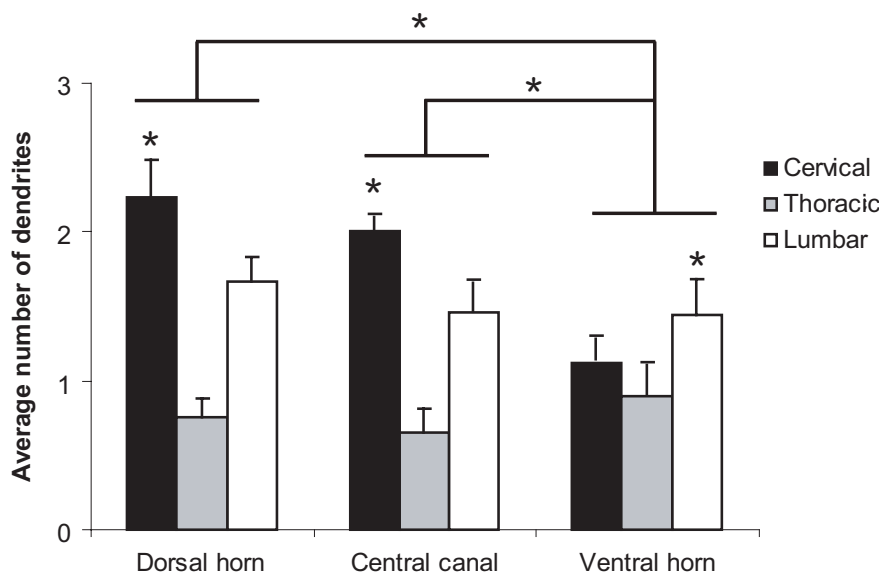

B
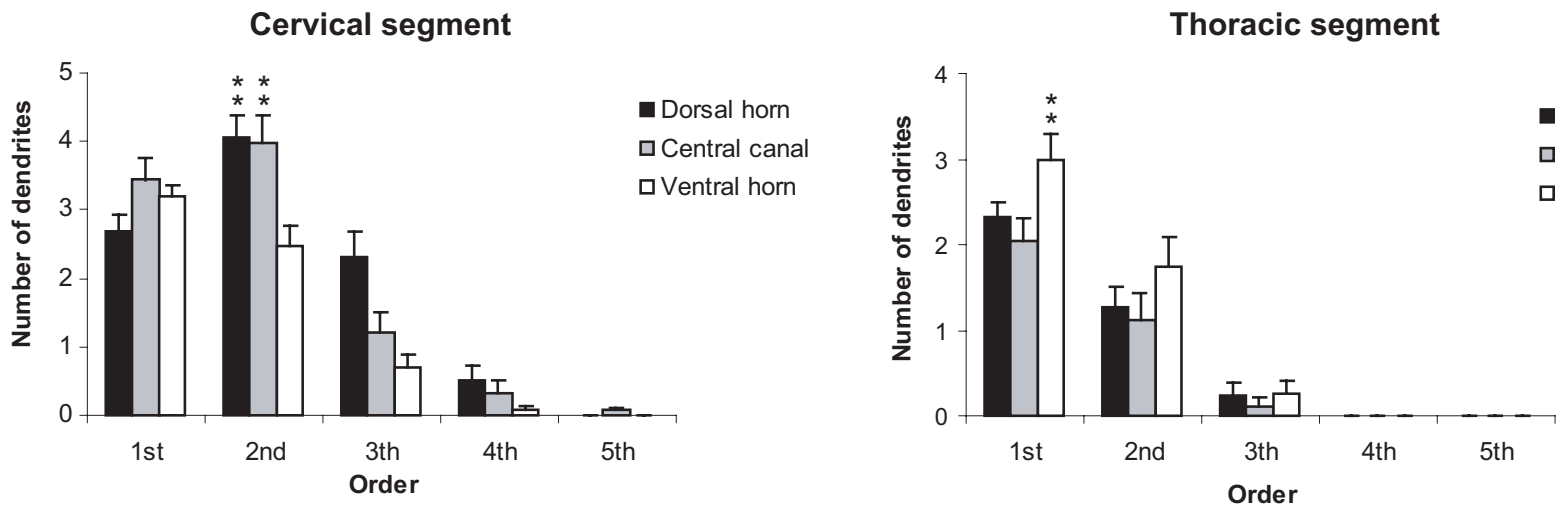

Dorsal horn

口Central canal

$\square$ Ventral horn

Central cana

Ventral horn

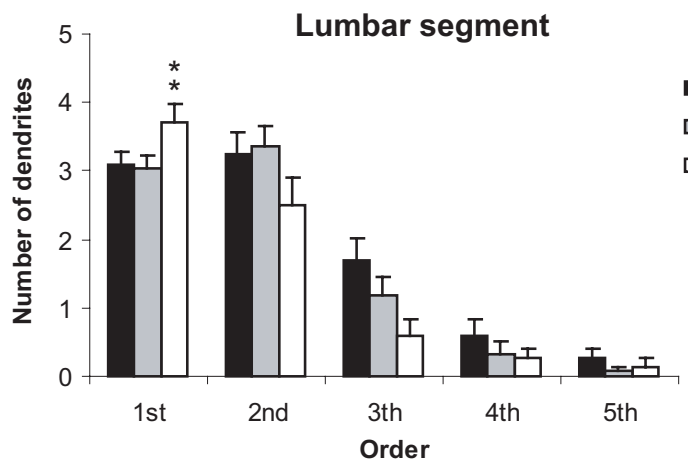

Figure 7. Ramification pattern in the spinal cord. Cells in the cervical enlargement are more ramified (in terms of average number of dendrites) in the dorsal horn and the central canal (A). Cells of the lumbar enlargement come in second and have the same ramification pattern in its three sub regions (dorsal horn, central canal and ventral horn). Cells in the lumbar and cervical enlargement have more complex dendritic patterns (B). Asterisks in horizontal bars indicate statistically significant comparisons $(* p<0.05 ; * * p<0.01)$.

the presence of type II neurons in otherwise successful histochemical reactions.

The presence of NADPH-d neurons in the dorsal horn superficial laminae is in accordance with the role played by NO in hyperalgesia and chronic pain in this region (Aley et al., 1998; Dolan et al., 2000; Ikeda et al., 2006; Tang et al., 2007; Wu et al., 1998). N0 would act on lamina I spinothalamic projection neurons contributing to activity-dependent LTP of synaptic responses evoked by peripheral inputs (Ruscheweyh et al., 2006; Simone et al., 1991). In the rat, for instance, a sustained production of NO and subsequent activation of soluble guanylate cyclase in the spinal cord mediates thermal hyperalgesia (Meller et al., 1992). NADPH-d neurons are also heavily concentrated in the central canal (lamina X), which has been shown to receive convergent input from visceral afferents and also from cutaneous, muscular, and noxious afferents (Ness and Gebhart, 1987; Wall et al., 2002). It is hypothesized that lamina X could mediate general arousal in the brain, in a way similar to the brainstem reticular formation (Wall et al., 2002).

Reactive NADPH-d neurons were also found in the IML, as described in other species (Kluchova et al., 2001; Marsala et al., 1999; Saito et al., 1994; Valtschanoff et al., 1992a). The IML is the anatomical substrate, or final common pathway, through which the control of the sympathetic nervous system is mediated by several inputs from the periphery (Appel 
and Elde, 1988), including noxious information. NADPH-d cells in this region are autonomic preganglionic neurons (Necker, 2004; Saito et al. 1994; Valtschanoff et al., 1992a). These cells form a local circuit which sends its projections, among their targets, to lamina $X$ (Saito et al., 1994). Thus, NO could act as a neuromodulator or neurotransmitter within sensory and motor circuits related to the pelvic viscera (Vizzard et al., 1993).

NO also plays a significant role in regulating cerebral blood flow in the CNS (Estrada and DeFelipe, 1998; Ishikawa et al., 2005; Yoshida et al., 1997). In the rabbit spinal cord, NADPH-d somata and fibers are closely associated with longitudinally oriented blood vessels (Marsala et al., 1999), suggesting that NO may also help to couple neural activity with regional blood flow in the spinal cord (Valtschanoff et al., 1992a).

The agouti uses its forelimbs for locomotion and to manipulate food while eating (see Santiago et al., 2007). Complex motor acts like these require continuous sensory feedback aimed at various levels of the motor hierarchy. It should be expected that in spinal cord segments involved with controlling movement of the limbs, especially the forelimb, the underlying circuitry should be more complex than in other segments This complexity could be expressed as a greater number of interneurons, for instance, or a tendency for neurons to have larger and more ramified dendritic trees. A larger dendritic field, for example, could serve to sample a greater diversity of inputs to the spinal cord circuits. We see this increase in morphological complexity happening, in terms of NADPH-d cells, both in the dorsal horn and central canal of the cervical enlargement. Conversely, and as a comparison, less morphological complexity and a smaller number of interneurons and motorneurons should be present in the thoracic segment, which controls axial muscles. The results presented here reinforce this hypothesis, supporting the notion that spinal cord regions that control axial muscles have fewer and morphologically simpler neurons than regions involved with more complex movements.

NADPH-d neurons in the white matter exhibited a well ramified dendritic arborization. The physiological role played by these cells is not clear yet, but it has been suggested that they belong to local circuits connecting different spinal segments (Marsala et al., 2003; Valtschanoff et al., 1992a).

\section{CONCLUSIONS}

In conclusion, the neuropil distribution of NADPH-d and $\mathrm{CO}$ in the spinal cord of the agouti is remarkably similar, both enzymes being more reactive in superficial laminae. This pattern is in accordance with the role played by NO in LTP of lamina I spinothalamic neurons. Two distinct types of NADPH-d-reactive neurons were also found: type I and type II neurons. Type I neurons are heavily stained and are located preferentially in superficial laminae, lamina X, IML, and the white matter. The dendritic field of type I neurons is more exuberant in cervical segments, which contain the final common pathways controlling skilled movements of the forelimbs. The resulting pattern of cell body and neuropil distribution is in accordance with segregation of function in the mammalian spinal cord and further illuminates the role played by NO in dorsal horn circuitry.

\section{CONFLICT OF INTEREST STATEMENT}

The authors declare that the research was conducted in the absence of any commercial or financial relationships that should be construed as a potential conflict of interest.

\section{ACKNOWLEDGEMENTS}

Research supported by grants from FUNTEC/SECTAM and CNPq (grant numbers 479578/2006-0 and 304422/2006-1). Additional financial support provided by FADESP, Financiadora de Estudos e Projetos (FINEP), and Associação Alberto Santos Dumont para Apoio à Pesquisa (AASDAP),
Brazil. This work was part of the requirements for the Master's degree obtained by Suzane Câmara Tourinho (PPGNBC/UFPA).

\section{REFERENCES}

Abercrombie, M. (1946). Estimation of nuclear population from microtome sections. Anat. Rec. 94, 239-247.

Aley, K. O., McCarter, G., and Levine, J. D. (1998). Nitric oxide signaling in pain and nociceptor sensitization in the rat. J. Neurosci. 18, 7008-7014.

Anderson C. R. (1992). NADPH diaphorase-positive neurons in the rat spinal cord include a subpopulation of autonomic preganglionic neurons. Neurosci. Lett. 139 , 280-284.

Appel, N. M., and Elde, R. P. (1988). The intermediolateral cell column of the thoracic spinal cord is comprised of target-specific subnuclei: evidence from retrograde transport studies and immunohistochemistry. J. Neurosci. 8, 1767-1775.

Barone, P., and Kennedy, H. (2000). Non-uniformity of neocortex: areal heterogeneity of NADPH-diaphorase reactive neurons in adult macaque monkeys. Cereb. Cortex 10, 160-174.

Blottner, D., and Baumgarten H. G. (1992). Nitric oxide synthetase (NOS)-containing sympathoadrenal cholinergic neurons of the rat IML-cell column: evidence from histochemistry, immunohistochemistry, and retrograde labeling. J. Comp. Neurol. $316,45-55$.

Calabrese, V., Mancuso, C., Calvani, M., Rizzarelli, E., Butterfield, D. A., and Stella, A. M. (2007). Nitric oxide in the central nervous system: neuroprotection versus neurotoxicity. Nat. Rev. Neurosci. 8, 766-775.

Contestabile, A. (2000). Roles of NMDA receptor activity and nitric oxide production in brain development. Brain Res. Brain Res. Rev. 32, 476-509.

Cruz-Rizzolo, R. J., Horta-Junior Jde, A., Bittencourt, J. C., Ervolino, E., de Oliveira, J. A., and Casatti C. A. (2006). Distribution of NADPH-diaphorase-positive neurons in the prefrontal cortex of the Cebus monkey. Brain Res. 1083, 118-133.

Dawson, T. M., Bredt, D. S., Fotuhi, M., Hwang, P. M., and Snyder, S. H. (1991). Nitric oxide synthase and neuronal NADPH diaphorase are identical in brain and peripheral tissues. Proc. Natl. Acad. Sci. USA 88, 7797-7801.

Dolan, S., Field, L. C., and Nolan, A. M. (2000). The role of nitric oxide and prostaglandin signaling pathways in spinal nociceptive processing in chronic inflammation. Pain $86,311-320$

Dun, N. J., Dun, S. L., Wu S. Y., Forstermann, U., Schmidt, H. H., and Tseng, L. F. (1993). Nitric oxide synthase immunoreactivity in the rat, mouse, cat and squirrel monkey spinal cord. Neuroscience 54, 845-857.

Elston, G. N., Elston, A., Freire, M. A. M., Gomes Leal, W., Pereira, A. Jr, Silveira, L. C., and Picanço-Diniz, C. W. (2006). Specialization of pyramidal cell structure in the visual areas V1, V2 and V3 of the South American rodent, Dasyprocta primnolopha. Brain Res. 1106, 99-110.

Estrada, C., and DeFelipe, J. (1998). Nitric oxide-producing neurons in the neocortex: morphological and functional relationship with intraparenchymal microvasculature. Cereb. Cortex 8, 193-203.

Foster, J. A., and Phelps, P. E. (2000). Neurons expressing NADPH-diaphorase in the developing human spinal cord. J. Comp. Neurol. 427, 417-427.

Freire, M. A. M., Franca, J. G., Picanço-Diniz, C. W., and Pereira, A. Jr (2005). Neuropil reactivity, distribution and morphology of NADPH diaphorase type I neurons in the barrel cortex of the adult mouse. J. Chem. Neuroanat. 30, 71-81.

Freire, M. A. M., Gomes-Leal, W., Carvalho, W. A., Guimarães, J. S., Franca, J. G., PicançoDiniz, C. W., and Pereira, A. Jr (2004). A morphometric study of the progressive changes on NADPH diaphorase activity in the developing rat's barrel field. Neurosci. Res. 50, 55-66.

Freire, M. A. M., Oliveira, R. B., Picanço-Diniz, C. W., and Pereira, A. Jr (2007). Differential effects of methylmercury intoxication in the rat's barrel field as evidenced by NADPH diaphorase histochemistry. Neurotoxicology 28, 175-181.

Gonchar, Y., Wang, Q., and Burkhalter, A. (2008). Multiple distinct subtypes of GABAergic neurons in mouse visual cortex identified by triple immunostaining. Front. Neuroanat. 1, 3. doi: 10.3389/neuro.05.003.2007.

Hassiotis, M., Paxinos, G., and Ashwell, K. W. (2005). Cyto- and chemoarchitecture of the cerebral cortex of an echidna (Tachyglossus aculeatus). II. Laminar organization and synaptic density. J. Comp. Neurol. 482, 94-122.

Henry, 0. (1999). Frugivory and the importance of seeds in the diet of the orange-rumped agouti (Dasyprocta leporina) in French Guiana. J. Trop. Ecol. 15, 291-300.

Holscher, C. (1997). Nitric oxide, the enigmatic neuronal messenger: its role in synaptic plasticity. Trends Neurosci. 20, 298-303.

Hope, B. T., Michael, G. J., Knigge, K. M., and Vincent, S. R. (1991). Neuronal NADPH diaphorase is a nitric oxide synthase. Proc. Natl. Acad. Sci. USA 88, 2811-2814.

ladecola, C. (1993). Regulation of the cerebral microcirculation during neural activity: is nitric oxide the missing link? Trends Neurosci. 16, 206-214.

Ikeda, H., Stark, J., Fischer, H., Wagner, M., Drdla, R., Jager, T., and Sandkuhler, J. (2006). Synaptic amplifier of inflammatory pain in the spinal dorsal horn. Science 312 , 1659-1662.

Ishikawa, M., Kajimura, M., Adachi, T., Maruyama, K., Makino, N., Goda, N., Yamaguchi, T., Sekizuka, E., and Suematsu, M. (2005). Carbon monoxide from heme oxygenase-2 is a tonic regulator against NO-dependent vasodilatation in the adult rat cerebral microcirculation. Circ. Res. 97, e104-e114. 
Kasischke, K. A., Vishwasrao, H. D., Fisher, P. J., Zipfel, W. R., and Webb, W. W. (2004) Neural activity triggers neuronal oxidative metabolism followed by astrocytic glycolysis. Science 305, 99-103.

Kluchova, D., Klimcik, R., and Kloc, P. (2002). Neuronal nitric oxide synthase in the rabbit spinal cord visualised by histochemical NADPH-diaphorase and immunohistochemical NOS methods. Gen. Physiol. Biophys. 21, 163-174.

Kluchova, D., Rybarova, S., Miklosova, M., Lovasova, K., Schmidtova, K., and Dorko, F. (2001). Comparative analysis of NADPH-diaphorase positive neurons in the rat, rabbit and pheasant thoracic spinal cord. A histochemical study. Eur. J. Histochem. 45, 239-248.

Luth, H. J., Hedlich, A., Hilbig, H., Winkelmann, E., and Mayer, B. (1994). Morphologica analyses of NADPH-diaphorase/nitric oxide synthase positive structures in human visual cortex. J. Neurocytol. 23, 770-782.

Marsala, J., Kluchova, D., and Marsala, M. (1997). Spinal cord gray matter layers rich in NADPH diaphorase-positive neurons are refractory to ischemia-reperfusioninduced injury: a histochemical and silver impregnation study in rabbit. Exp. Neurol. 145, 165-179.

Marsala, J., Marsala, M., Lukacova, N., Ishikawa, T., and Cizkova, D. (2003). Localization and distribution patterns of nicotinamide adenine dinucleotide phosphate diaphorase exhibiting axons in the white matter of the spinal cord of the rabbit. Cell. Mol. Neurobiol. 23, 57-92.

Marsala, J., Marsala, M., Vanicky, I., and Taira, Y. (1999). Localization of NADPHd-exhibiting neurons in the spinal cord of the rabbit. J. Comp. Neurol. 406, 263-284.

Meller, S. T., Pechman, P. S., Gebhart, G. F., and Maves, T. J. (1992). Nitric oxide mediates the thermal hyperalgesia produced in a model of neuropathic pain in the rat. Neuroscience 50, 7-10.

Mizukawa, K., Vincent, S. R., McGeer, P. L., and McGeer, E. G. (1989). Distribution of reduced-nicotinamide-adenine-dinucleotide-phosphate diaphorase-positive cells and fibers in the cat central nervous system. J. Comp. Neurol. 279, 281-311.

Molander, C., Xu, Q., and Grant, G. (1984). The cytoarchitectonic organization of the spinal cord in the rat. I. The lower thoracic and lumbosacral cord. J. Comp. Neurol. 230, 133-141.

Molander, C., Xu, Q., Rivero-Melian, C., and Grant, G. (1989). Cytoarchitectonic organization of the spinal cord in the rat: II. The cervical and upper thoracic cord. J. Comp. Neurol. 289, 375-385.

Necker, R. (2004). Distribution of choline acetyltransferase and NADPH diaphorase in the spinal cord of the pigeon. Anat. Embryol. 208, 169-181.

Ness, T. J., and Gebhart, G. F. (1987). Characterization of neuronal responses to noxious visceral and somatic stimuli in the medial lumbosacral spinal cord of the rat J. Neurophysiol. 57, 1867-1892.

Ouda, L., Nwabueze-Ogbo, F. C., Druga, R., and Syka, J. (2003). NADPH-diaphorasepositive neurons in the auditory cortex of young and old rats. Neuroreport 14 363-366.

Pereira, A. Jr , Freire, M. A. M., Bahia, C. P., Franca, J. G., and Picanço-Diniz, C. W. (2000). The barrel field of the adult mouse Sml cortex as revealed by NADPH-diaphorase histochemistry. Neuroreport 11, 1889-1892.

Picanço-Diniz, C. W., Oliveira, H. L., Silveira, L. C., and Oswaldo-Cruz, E. (1989). The visual cortex of the agouti (Dasyprocta aguti): architectonic subdivisions. Braz. J. Med. Biol. Res. 22, 121-138.

Reuss, M. H., and Reuss, S. (2001). Nitric oxide synthase neurons in the rodent spinal cord: distribution, relation to Substance $P$ fibers, and effects of dorsal rhizotomy. J. Chem. Neuroanat. 21, 181-196.

Rexed, B. (1952). The cytoarchitectonic organization of the spinal cord in the cat. J. Comp. Neurol. 96, 414-495.

Rexed, B. (1954). A cytoarchitectonic atlas of the spinal cord in the cat. J. Comp. Neurol. 100, 297-379.

Rocha, E. G., Santiago, L. F., Freire, M. A. M., Gomes-Leal, W., Lent, R., Houzel, J. C., Franca, J. G., Pereira, A. Jr, and Picanço-Diniz, C. W. (2007). Callosal axon arbors in the limb representations of the somatosensory cortex (SI) in the agouti (Dasyprocta primnolopha). J. Comp. Neurol. 500, 255-266.

Ruscheweyh, R., Goralczyk, A., Wunderbaldinger, G., Schober, A., and Sandkuhler, J. (2006). Possible sources and sites of action of the nitric oxide involved in synaptic plasticity at spinal lamina I projection neurons. Neuroscience 141, 977-988.

Saito, S., Kidd, G. J., Trapp, B. D., Dawson, T. M., Bredt, D. S., Wilson, D. A., Traystman R. J., Snyder, S. H., and Hanley, D. F. (1994). Rat spinal cord neurons contain nitric oxide synthase. Neuroscience $59,447-456$.

Sandell, J. H. (1986). NADPH diaphorase histochemistry in the macaque striate cortex. J. Comp. Neurol. 251, 388-397.

Santiago, L. F., Rocha, E. G., Freire, M. A. M., Lent, R., Houzel, J. C., Picanço-Diniz, C. W. Pereira, A. Jr, and Franca, J. G. (2007). The organizational variability of the rodent somatosensory cortex. Rev. Neurosci. 18, 283-294.

Scherer-Singler, U., Vincent, S. R., Kimura, H., and McGeer, E. G. (1983). Demonstration of a unique population of neurons with NADPH-diaphorase histochemistry. J. Neurosci. Methods 9, 229-234.

Schoenen, J. (1973). Cytoarchitectonic organization of the spinal cord in different mammals including man. Acta Neurol. Belg. 73, 348-358.
Silveira, L. C., Picanço-Diniz, C. W., and Oswaldo-Cruz, E. (1989). Distribution and size of ganglion cells in the retinae of large Amazon rodents. Vis. Neurosci. 2, 221-235.

Silvius, K. M., and Fragoso, J. M. V. (2003). Red-rumped agouti (Dasyprocta leporina) home range use in an Amazonian forest: implications for the aggregated distribution of forest trees. Biotropica 35, 74-83.

Simone, D. A., Sorkin, L. S., Oh, U., Chung, J. M., Owens, C., LaMotte, R. H., and Willis, W. D. (1991). Neurogenic hyperalgesia: central neural correlates in responses of spinothalamic tract neurons. J. Neurophysiol. 66, 228-246.

Smithson, I. L., and Benarroch, E. E. (1996). Organization of NADPH-diaphorase-reactive neurons and catecholaminergic fibers in human intermediolateral cell column. Brain Res. 723, 218-222.

Spike, R. C., Todd, A. J., and Johnston, H. M. (1993). Coexistence of NADPH diaphorase with GABA, glycine, and acetylcholine in rat spinal cord. J. Comp. Neurol. 335, 320-333.

Tang, Q., Svensson, C. I., Fitzsimmons, B., Webb, M., Yaksh, T. L., and Hua, X. Y. (2007) Inhibition of spinal constitutive NOS-2 by $1400 \mathrm{~W}$ attenuates tissue injury and inflammation-induced hyperalgesia and spinal p38 activation. Eur. J. Neurosci. 25, 2964-2972.

Thomas, E., and Pearse, A. G. (1964). The solitary active cells. Histochemical demonstration of damage-resistant nerve cells with a TPN-diaphorase reaction. Acta Neuropathol. 27, 238-249.

Valtschanoff, J. G., Weinberg, R. J., Kharazia, V. N., Schmidt, H. H., Nakane, M., and Rustioni, A. (1993). Neurons in rat cerebral cortex that synthesize nitric oxide: NADPH diaphorase histochemistry, NOS immunocytochemistry, and colocalization with GABA. Neurosci. Lett. 157, 157-161.

Valtschanoff, J. G., Weinberg, R. J., and Rustioni, A. (1992a). NADPH diaphorase in the spinal cord of rats. J. Comp. Neurol. 321, 209-222.

Valtschanoff, J. G., Weinberg, R. J., Rustioni, A., and Schmidt, H. H. (1992b). Nitric oxide synthase and GABA colocalize in lamina II of rat spinal cord. Neurosci. Lett. 148, 6-10.

Vincent, S. R., and Hope, B. T. (1992). Neurons that say NO. Trends Neurosci. 15, 108-113.

Vincent, S. R., and Kimura, H. (1992). Histochemical mapping of nitric oxide synthase in the rat brain. Neuroscience 46, 755-784.

Vizzard, M. A., Erdman, S. L., and de Groat, W. C. (1993). Localization of NADPHdiaphorase in pelvic afferent and efferent pathways of the rat. Neurosci. Lett. 152, 72-76.

Wall, P. D., Kerr, B. J., and Ramer, M. S. (2002). Primary afferent input to and receptive field properties of cells in rat lumbar area X. J. Comp. Neurol. 449, 298-306.

Wallace, M. N., Tayebjee, M. H., Rana, F. S., Farquhar, D. A., and Nyong'0, A. O. (1996). Pyramidal neurones in pathological human motor cortex express nitric oxide synthase. Neurosci. Lett. 212, 187-190.

Wiencken, A. E., and Casagrande, V. A. (2000). The distribution of NADPH diaphorase and nitric oxide synthetase (NOS) in relation to the functional compartments of areas V1 and V2 of primate visual cortex. Cereb. Cortex 10, 499-511.

Williams, R. W., and Rakic, P. (1988). Three-dimensional counting: an accurate and direct method to estimate numbers of cells in sectioned material. J. Comp. Neurol. 278 , 344-352.

Wong-Riley, M. (1979). Columnar cortico-cortical interconnections within the visual system of the squirrel and macaque monkeys. Brain Res. 162, 201-217.

Wong-Riley, M. T. (1989). Cytochrome oxidase: an endogenous metabolic marker for neuronal activity. Trends Neurosci. 12, 94-101.

Wong-Riley, M. T., and Kageyama, G. H. (1986). Localization of cytochrome oxidase in the mammalian spinal cord and dorsal root ganglia, with quantitative analysis of ventral horn cells in monkeys. J. Comp. Neurol. 245, 41-61.

Wong-Riley, M. T., and Welt, C. (1980). Histochemical changes in cytochrome oxidase of cortical barrels after vibrissal removal in neonatal and adult mice. Proc. Natl. Acad. Sci. USA 77, 2333-2337.

Woolf, C. J. (1983). Evidence for a central component of post-injury pain hypersensitivity. Nature 306, 686-688.

Wu, J., Lin, Q., Lu, Y., Willis, W. D., and Westlund, K. N. (1998). Changes in nitric oxide synthase isoforms in the spinal cord of rat following induction of chronic arthritis. Exp. Brain Res. 118, 457-465.

Xiao, Y. M., Diao, Y. C., and So, K. F. (1996). A morphological study of neurons expressing NADPH diaphorase activity in the visual cortex of the golden hamster. Brain Behav. Evol. 48, 221-230.

Yan, X. X., and Garey, L. J. (1997). Morphological diversity of nitric oxide synthesising neurons in mammalian cerebral cortex. J. Hirnforsch. 38, 165-172.

Yan, X. X., Jen, L. S., and Garey, L. J. (1996). NADPH-diaphorase-positive neurons in primate cerebral cortex colocalize with GABA and calcium-binding proteins. Cereb. Cortex 6, 524-529.

Yonehara, N., Takemura, M., Yoshimura, M., Iwase, K., Seo, H. G., Taniguchi, N., and Shigenaga, Y. (1997). Nitric oxide in the rat spinal cord in Freund's adjuvant-induced hyperalgesia. Jpn. J. Pharmacol. 75, 327-335.

Yoshida, M., Kurose, I., Wakabayashi, G., Hokari, R., Ishikawa, H., Otani, Y., Shimazu, M., Miura, S., Ishii, H., and Kitajima, M. (1997). Suppressed production of nitric oxide as a cause of irregular constriction of gastric venules induced by thermal injury in rats. J. Clin. Gastroenterol. 25(Suppl. 1), S56-S60. 